\title{
Prevalence of rheumatic fever/rheumatic heart disease among school children of age group 5-15 years in district Jammu
}

\author{
DS Jamwal ${ }^{1}$, Rakesh Bahl', ${ }^{2,}$, Rayaz Jan ${ }^{3}$, Mohan Lal ${ }^{4}$, Bhupinder Singh ${ }^{5}$ \\ ${ }^{\mathbf{1}}$ Associate Professor, ${ }^{2}$ Lecturer, ${ }^{3}$ Research Officer, ${ }^{4,5}$ Professor and Head, ${ }^{\mathbf{1 - 3 , 5}}$ Dept. of Community Medicine, ${ }^{4}$ Dept. of \\ Cardiology, Government Medical College, Jammu, (J\&K), India
}

*Corresponding Author:

Email: rbrakeshbahl@gmail.com

\begin{abstract}
Introduction: Rheumatic fever and rheumatic heart disease are major cause of valvular heart disease in the world. It is estimated that up to 15.6 million people worldwide are affected by rheumatic heart disease and every year approximately 470,000 new cases are detected and 2,33,000 deaths are attributed to rheumatic heart disease.

Objective: A study was conducted by department of Community medicine, Government Medical College Jammu (J\&K) to assess the prevalence of rheumatic fever and rheumatic heart disease among school children in age group of 5-15 years, in Jammu district.

Materials and Methods: A cross sectional study involving the screening of school children drawn from schools of Jammu district as a part of a research project of ICMR under Jai Vigyan Mission Mode (JVMM). Participants included ten thousand students of schools of Jammu district in ten age slots in age group of 5-15years, each having 1000 children.

Setting: The schools were selected by stratified systematic random sampling technique such that half of children (5000) belonged to rural schools and half (5000) to urban schools with equal sex distribution as well as equal government private distribution.

Study Period: May 2007 to March 2010.

Results: Prevalence of rheumatic fever and rheumatic heart disease were found to be respectively $0.7 / 1000$ and $0.6 / 1000$ school children in age group 5-15 years.

Conclusion: Keeping in view these results, the burden of rheumatic fever and rheumatic heart disease on the public health system for chemoprophylaxis and surgery cannot be ignored. Hence, although on a decline, but still rheumatic fever and rheumatic heart disease remain a public health problem for the young populations aged 05-15 years in this part of country.
\end{abstract}

Keywords: Rheumatic fever, Rheumatic heart disease, Children 5-15 years, Jammu.

\section{Introduction}

Rheumatic fever is an inflammatory disease that can develop as a complication of inadequately treated sore throat due to Group A beta haemolytic streptococcal infection. It is most common in 5 to 15 year old children, though it can develop in younger children and adults also. Although, streptococcal sore throat is common but, rheumatic fever occurs among few of the cases. It can cause permanent damage to the heart, including damaged heart valves leading to rheumatic heart disease which is a debilitating condition. Rheumatic fever usually sets in about some weeks after a Group A beta haemolytic streptococcal throat infection. Symptoms usually occur due to inflammation in the heart valves, central nervous system, or joints and include fleeting type of arthritis involving large joints (wrists, ankles), palpitations, breathlessness, excessive fatigue.

Rheumatic heart disease is a major cause of valvular heart disease in the world presenting with various defects including stenosis and regurgitation of mainly mitral and aortic valves followed by same lesions of pulmonary and tricuspid valves leading to a crippled life. Though, in the developed countries, acute rheumatic fever and rheumatic heart disease have declined considerably, it is estimated that up to 15.6 million people worldwide are affected by rheumatic heart disease and every year approximately 470,000 new cases and 2,33,000 deaths are attributed to rheumatic heart disease. ${ }^{1}$ There is no data available on the subject in $\mathrm{J} \& \mathrm{~K}$, hence a study was conducted by department of Community medicine, Government Medical College Jammu (J\&K) to study the prevalence of rheumatic fever and rheumatic heart disease among school children in age group of 5-15 years, in Jammu district.

\section{Materials and Methods}

Study Design: A cross sectional study involving the screening of school children drawn from schools of Jammu district.

Participants: Students of schools of Jammu district had been chosen for the survey. It was planned to cover 10,000 school children in age group of 5-15 years divided into 10 subgroups (5-6yrs, 6-7yrs, 7-8 years...14-15 years) each having 1000 children.

Setting: There are a total of 2614 schools including 472 high schools, 750 middle schools and 1392 primary schools were selected by stratified systematic random sampling technique such that half of children (5000) belonged to rural schools and half (5000) to urban schools. These groups were divided equally into government and private schools and finally in each group half were girls and half were boys. This way we 
had eight different groups in each of ten age groups each comprising of 125 students making a total of eighty groups.

Study Variables: Age, sex, history of sore throat, history suggestive of signs and symptoms of rheumatic heart disease/rheumatic fever among the students. Clinical examination included general physical examination with special attention to any cardiac murmur or any other sign suggestive of rheumatic fever/rheumatic heart disease.

The diagnosis of rheumatic fever was based on Jone's criteria:

Major Criteria: i). Carditis, ii). Polyarthritis, iii). Chorea, iv). Erythema marginatum, v). Subcutaneous nodules

Minor Criteria: i). Fever, ii). Arthralgia, iii). Previous $\mathrm{H} / \mathrm{O}$ rheumatic fever or rheumatic heart disease, iv). Raised ESR, ASO titre, $\mathrm{C}$ reactive proteins, leucocytosis, v). Prolonged PR interval in ECG.

Presence of any two major criteria or one major plus two minor criteria makes the diagnosis of rheumatic fever.

All suspected cases were referred to cardiologist for confirmation of diagnosis and investigations (ECG, Echocardiography) wherever advised by him.

Throat swabs were collected from cases of sore throat and carried in vaccine career to Microbiology laboratory on same day

Procedure of Data Collection: A list of all schools (Government and private) in rural and urban areas separately in Jammu district was obtained from the department of school education. The schools were selected by draw of lots and lists prepared. Head of each school was contacted by the investigators a few days before the tentative visit to get their cooperation by explaining the need for the survey. All the eligible students present on the day of school survey were screened for Sore throat and subjected to general physical examination to screen for any cardiac abnormality in the form of any murmur suggesting a suspected rheumatic heart disease. All such suspected cases were referred to the Cardiologist for clinical examination and Echocardiography if the cardiologist felt the need. The throat swabs collected from the school children used to be returned to the Microbiology department on the same day in a cold box for culture. To include the students absent on that day, second and third visit (if required) were paid to school. The study continued till the target of screening the students in each age group was achieved.

Study Period: 01 May 2007 to 31 March 2010.

\section{Results}

Rheumatic Fever: Target of screening the school children was achieved in 30 months period. Out of ten thousand school children surveyed, seven cases of rheumatic fever could be detected according to Jone's criteria and confirmed by the cardiologist and paediatrician. The distribution is given in Table 1 below:

Table 1: Age and sex distribution of cases of rheumatic fever among school children age 5-15 years

\begin{tabular}{|c|c|c|c|c|c|c|c|c|}
\hline \multicolumn{4}{|c|}{ Age Group 5-10 years } & \multicolumn{3}{c|}{ Age Group 10-15 years } & \multicolumn{3}{c|}{ Age group 5-15 years } \\
\hline Male & Female & Total & Male & Female & Total & Male & Female & Total \\
\hline 02 & 01 & 03 & 01 & 03 & 04 & 03 & 04 & 07 \\
\hline
\end{tabular}

Prevalence of rheumatic fever was found to be $0.7 / 1$ s000 school children in age group 5-15 years.

a. Rheumatic Heart Disease: total of ten thousand school children in the age group of 5-15 years were examined during study. Murmurs were detected in 277 participants. They were referred to cardiologist for confirmation. Cardiologist excluded 194 cases as insignificant murmurs and subjected the rest 83 to echocardiography. In case of 72 children echocardiography showed normal report whereas six were confirmed as rheumatic heart disease and 5 were confirmed as congenital heart disease. The details of the cases are given in Table 2.

Table 2: Age \& sex distribution of cases of rheumatic heart disease among school children age 5-15 years

\begin{tabular}{|c|c|c|c|c|c|c|c|c|c|}
\hline & \multicolumn{3}{|c|}{ Age Group 5-10years } & \multicolumn{3}{c|}{ Age Group 10-15 years } & \multicolumn{3}{c|}{ All Participants 5-15 years } \\
\hline Sex & Male & Female & Total & Male & Female & Total & Male & Female & Total \\
\hline No & 02 & 03 & 05 & 01 & 00 & 01 & 03 & O3 & 06 \\
\hline$\%$ & 40 & 60 & 100 & 100 & 00 & 100 & 50 & 50 & 100 \\
\hline
\end{tabular}

Prevalence of rheumatic heart disease among age group of 5-15 years was 0.6/ 1000 population.

\section{Discussion}

The study was conducted by department of Community medicine, Government Medical College, Jammu (J\&K) to study the prevalence of rheumatic fever and rheumatic heart disease among school children in Jammu district. It was carried out by active case finding through school survey covering 10,000 students in age group of 5-15 years.

Prevalence of rheumatic fever among children aged $5-15$ years was found as 0.7/1000 (Boys $=0.6 / 1000$ and 
Girls $=0.8 / 1000)$. It goes contrary to the findings of a similar study conducted by Indian Council of Medical Research (2000-2010) in 10 different, mostly urban, locations of the country showing the prevalence between 0.0007 to $0.2 / 1000$ for rheumatic fever. ${ }^{6}$ The data were based on registration of all cases in one million population by approaching hospitals, private practitioners and extensive advertising for establishing a registry of all known cases. Our study has shown higher values because it included rural and urban populations in equal proportions and the total prevalence could have been high due to higher prevalence among the rural children. ${ }^{2}$ Since the methodology adopted was similar, our study results seem to be dependable.

In the present study, prevalence of echocardiographically confirmed rheumatic heart disease among students of age 5-15 years was found to be $0.6 / 1000$. It is comparatively much less than the results shown by a similar study conducted by Mathur $\mathrm{KS}$ et al on rheumatic heart disease and rheumatic fever in a village community of Bichpuri block Agra where it was found to be $1.8 / 1000$ in the same age group. ${ }^{3}$ Similarly the results are lower than the ones depicted in work carried out by Misra M et al in Punjab, Gujarat, Rajasthan, Uttar Pradesh and Tamil Nadu wherein the prevalence ranged from 0.67 to $4.54 / 1000$ children. The figures are variable but suggest a decline in the prevalence of rheumatic heart disease over time. ${ }^{4}$ Hence, we can construe that the prevalence of rheumatic heart disease is on decline in our population as well.

Among the 6 rheumatic heart disease cases, the sex distribution was equal (Boys=3; Girls=3). However, it was higher among girls in age 5-10 years and higher in boys in age group 10-15 years. In many studies the prevalence was found to be higher among girls. Almost similar sex distribution was observed in a similar study carried out by Berry et al in urban population of Chandigarh which found rheumatic heart disease distribution of $37.28 \%(1.23 / 1000)$ among boys and $62.72 \%(2.07 / 1000)$ among the girls of all age groups. ${ }^{5}$

In a study conducted by Indian Council of Medical Research (ICMR) (2000 - 2010) in 10 different, mostly urban, locations of the country found the prevalence to range from 0.2 to $1.1 / 1000$ for rheumatic heart disease. ${ }^{6}$ The data were based on registration of all cases in one million population by approaching hospitals, private practitioners and extensive advertising for establishing a registry of all known cases. This study has shown results comparable to the national level study in terms of rheumatic heart disease $(0.6 / 1000)$.

\section{Conclusion}

If the prevalence rates for rheumatic fever and rheumatic heart disease are computed to absolute figures, then in a population of 3,75,000 children in age group 5-15 years, then in Jammu district at any given time 263 cases of rheumatic fever and 225 cases of rheumatic heart disease can be present who need chemoprophylaxis and follow up with need for surgery at a later stage. Keeping in view these figures the burden of rheumatic fever and rheumatic heart disease on the public health system cannot be ignored. Hence, although on a decline, but still rheumatic fever and rheumatic heart disease remain a public health problem for the young populations aged 05-15 years in this part of country.

\section{References}

1. A study by carapetis et al: Rheumatic Heart Disease in Asia: Menzies school of health research, Charles Darwin university, Darwin, Australia.

2. Bhardwaj R, kandoria A, Marwah R, Vaidya P, Singh B, Dhiman P et al: Prevalence of Rheumatic Fever and Rheumatic Heart Disease in rural population of Himachal- A population based study: journal of association of physicians of India.

3. Mathur KS, Banerji SC, Nigam DK, Prasad R. Rheumatic Heart Disease and Rheumatic Fever-prevalence in a village community of Bichpuri Block Agra. J Assoc Physicians India 1971;19:151-6.

4. Misra M, Mittal M, Singh R, Verma A, Rai R, Chandra $\mathrm{G}$, et al. Prevalence of Rheumatic Heart Disease in school-going children of Eastern Uttar Pradesh, Indian. Heart J 2007;59:42-3.)

5. Berry JN. Prevalence survey of chronic rheumatic heart disease and Rheumatic Fever in Northern India. Br Heart $J, 1972 ; 34: 134-49$.

6. ICMR Jai Vigyan Mission Mode Project (registry component); Report: 2010. 